Original Research Paper

\title{
Experimental Antenna and Circuit Model for Charging an Electronic Device from the Ambient Electromagnetic Waves
}

\author{
${ }^{1}$ Pankaj Chandra Kar, ${ }^{2}$ Md Ariful Islam, ${ }^{3}$ Amit Paul, ${ }^{4}$ Joydip Chakrabarti, \\ ${ }^{5}$ Subrata Sutradhar and ${ }^{6}$ Fardin Teen Rahman \\ ${ }^{1,4}$ Department of Information and Communication Technology, Comilla University, Cumilla, Bangladesh \\ ${ }^{2}$ Department of Robotics and Mechatronics Engineering, University of Dhaka, Dhaka, Bangladesh \\ ${ }^{3}$ Department of Physics, Comilla University, Cumilla, Bangladesh \\ ${ }^{5}$ Department of Mathematics, Comilla Victoria Government College, Cumilla, Bangladesh \\ ${ }^{6}$ Department of Mechanical Engineering, Queen Mary University of London, United Kingdom
}

\author{
Article history \\ Received: 06-04-2021 \\ Revised: 26-04-2021 \\ Accepted: 14-05-2021 \\ Corresponding Author: \\ Pankaj Chandra Kar \\ Department of Information and \\ Communication Technology, \\ Comilla University, Cumilla, \\ Bangladesh \\ Email: pankajkarcouict@gmail.com
}

\section{Introduction}

Electromagnetic radiation is still there and all over us. Natural or man-made energy may come from either earthly or extraterrestrial sources. The emanations targeted by an intruder are energy encoded with information that is radiated from electronic devices. Electromagnetic waves are the product of such emanations and these waves follow the physical rules. As a result, these rules control the conduct of messages that must be protected from being tampered with (Norman, 2014). Electromagnetic waves have long been used for a wide variety of applications, e.g., communications, radar, remote sensing heating, medical applications, etc. Recently, the use of electronic devices has increased a lot. Electromagnetic radiation (EM radiation) refers to the waves (or their quanta, photons) of the electromagnetic field (Purcell et al., 1965), propagating (radiating) through space, carrying electromagnetic radiant energy.

Figure 1 shows that the electric field and magnetic field are perpendicular to each other and their resultant field (electromagnetic field) is perpendicular to both of them.
Electric and magnetic fields obey the properties of superposition. Thus, a field due to any particular particle or time-varying electric or magnetic field contributes to the fields present in the same space due to other causes.

\section{Electromagnetic Wave}

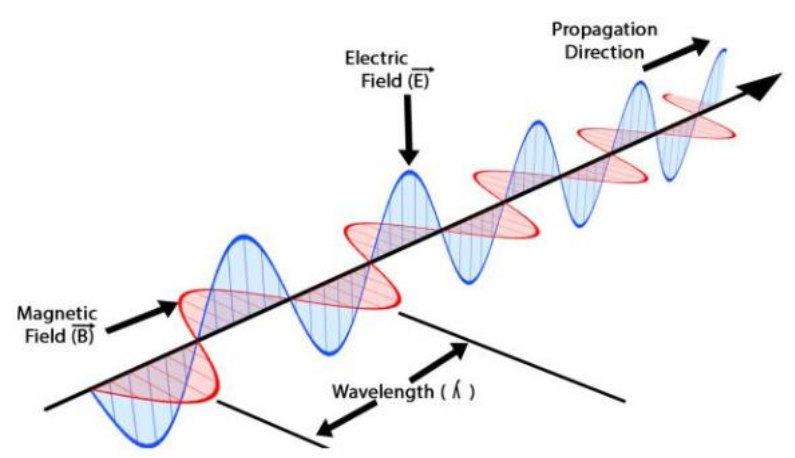

Fig. 1: Electromagnetic wave (Browne, 2013) 
Both the electric and magnetic field vectors are perpendicular to each other in an electromagnetic wave. When it is passed through a helical coil such as the solenoid or even an inductor, a steady magnetic field is produced along the axis of the coil. Both magnetic and electric fields are related to each other (Browne, 2013). Further, as they are vector fields, all magnetic and electric field vectors are added together according to vector addition (Cloude, 1995). Electromagnetic waves are emitted by electrically charged particles undergoing acceleration (Bettini, 2016) and these waves can subsequently interact with other charged particles, exerting force on them. EM waves carry energy, momentum, and angular momentum away from their source particle and can impart those quantities to the matter with which they interact. Electromagnetic radiation is associated with those EM waves that are free to propagate themselves ('radiate') without the continuing influence of the moving charges that produced them because they have achieved sufficient distance from those charges. Thus, EMR is sometimes referred to as the farfield. In this language, the near field refers to EM fields near the charges and current that directly produced them, specifically electromagnetic induction and electrostatic induction phenomena. The wire is electrically neutral. For every electron in the wire, there is a proton, so the electron traveling alongside should feel no pull towards the wire or a push away (Kraus and Williamson, 1948). Axialmode helical antennas are one of the excellent candidates for achieving circular polarizations in wireless communications due to their advantages such as high gain and wide Axial Ratio (AR) bandwidth (Kraus, 1949; Dennison et al., 2002). Despite the progress of classical electromagnetic theory in dealing with light propagation, interference, and scattering, research performed towards the end of the nineteenth century and the beginning of the twentieth century culminated in the reintroduction of the corpuscular theory, albeit in a different form than Newton suggested (Nakano et al., 1991).

Electronic gadgets and screens are being used more often and children are exposed to devices at younger and younger ages. Our use of devices such as televisions, computers, laptops, e-readers, and cell phones has increased exponentially over the past few decades (Tang et al., 2016a). The calculated model for charging an electronic device from the ambient EM waves is unusual in the literature (Tang et al., 2016b; Zeain et al., 2020; Guo et al., 2016; Kar et al., 2021; Dai et al., 2016; Kindl et al., 2020; Jiang et al., 2012; Beh et al., 2014; Zeng et al., 2017), despite its importance for coverage forecasts. Using the previous approaches, the induced voltage was so low. The bulk of the time, consumers have a difficult time charging their devices. No paper expresses a straightforward understanding of the proposed model. At different frequency networks, this study provides an approximate model for charging a device. The ambient waves are received using a helical antenna. During propagation, a small voltage is induced. A step-up transformer is used to amplify this induced voltage. A sensor is used to control the switching circuit. If the remaining charge is less than $20 \%$ of the total battery charge, the sensor sends a signal to the switching circuit. Then the switch becomes closed and this state will continue until $2 \mathrm{~h}$ which can be modified. By implementing this model, charging problems can be reduced.

\section{Related Work}

Zeain et al. (2020), the authors suggested a striphelical antenna with a parasitic circular patch for circular polarization. Two nearby Circularly Polarized (CP) resonances were created and a broad Axial Ratio (AR) bandwidth was obtained by combining the strip-helix and the parasitic patch.

Using Teflon material, the authors created a helical antenna that achieves circular polarization without impedance matching at $5.8 \mathrm{GHz}$. The helical antenna on the Teflon substrate achieves a wideband bandwidth of $2.41 \mathrm{GHz}$ with a resonant frequency of $5.8 \mathrm{GHz}$ (Tang et al., 2016a).

The authors of (Guo et al., 2016) proposed an experimental circuit model to increase the signal intensity in the lift. All of the EM waves were processed using an outdoor antenna. To transmit a particular signal, a resonant circuit was used. The signal was amplified using an amplifier circuit. In the elevator, an indoor antenna was used.

A 1.1-turn wideband strip-helical antenna was numerically and experimentally studied. With 50-ohm impedance matching, the strip helix will excite a wideband Circular Polarization (CP) wave. To have a directional radiation pattern, a ground plane was mounted underneath the antenna. The suggested antenna was printed on a hollow-cylinder substrate with $\varepsilon_{r}=2.2$ relative permittivity and $\mathrm{h}=0.5 \mathrm{~mm}$ thickness (Kar et al., 2021).

The authors created the Concurrent Charging Scheduling Problem (CCSP) based on the concurrent charging paradigm, with the goal of rapidly completely charging all of the sensor nodes. Following the proof of CCSP's NP-hardness, two effective greedy algorithms were suggested, with the approximation ratio of one of them. With a small network and charger scales, all greedy algorithms performed almost as well as a well-designed Genetic Algorithm (GA), which performs almost as well as a brute force algorithm (Dai et al., 2016).

PESA, a wireless charger positioning system, was suggested by the authors (Kindl et al., 2020). Any location on the plane was secure from EMR. They discretized the entire charging area and formulated the problem as a Multidimensional 0/1 Knapsack (MDK) problem with a short approximation algorithm. 
Jiang et al. (2012), the computational modeling phase was concerned with high-power wireless power transmission systems. They looked at the inductive magnetic coupler's electromagnetic nature and suggested core formulas for optimizing its electrical parameters for a specific load. The system was used to charge the battery as well as the resistive load.

Wireless chargers for Electric Vehicles (EVs) would also be a useful feature, as they would eliminate the need to remember to plug in the car after parking. Wireless charging for electric vehicles is an application that necessitates high electrical capacity (up to hundreds of kilowatts) and a greater wireless power transmission region, resulting in increased electromagnetic field exposure. The dilemma was addressed using the Hazard Based Safety Engineering (HBSE) concept and the UL training curriculum was implemented (Beh et al., 2014).

The architectures of closely coupled lumped magnetic couplers were explored (Zeng et al., 2017). For the side and bracket stands, a cylindrical solenoidal vertical Pickup (PU) and a horizontal solenoidal bar PU were also studied. A solenoidal bar PU with a double-D primary was shown to have good coupling and low magnetic field emissions.

A wireless charging coupler with a high coupling coefficient can increase transmission speed. The equivalent magnetic circuit and the expression of the coupling coefficient are obtained to achieve a higher coupling coefficient of a Double D (DD) coupler, providing some instructions for magnetic core optimization (Huang et al., 2019).

The authors suggest a new Selectable Regional Charging Wireless Power Transfer (SRC-WPT) device that can simultaneously charge multiple receivers. The SRC-WPT configuration used a transmitter array with different WPT frequency characteristics, with relays controlling the line (Norman, 2014).

The authors suggest an experimental circuit model for increasing the signal strength of a mobile phone in the lift. The proposed model demonstrates that the signal intensity level is nearly constant during the lift (Kar et al., 2021).

\section{Methodology}

\section{Key Factors of Receiving Electromagnetic Waves}

\section{Antenna Polarization}

The time-changing action of the electric field strength vector at some point in space is referred to as the polarization of a uniform plane wave (Kraus and Williamson, 1948). In general, the power loss due to polarization mismatch is defined by the Polarization Loss Factor, which is given by the equation for two linearly polarized antennas that are rotated by an angle $\phi$ :

$$
\text { Polarization Loss Factor }=\cos ^{2} \varphi
$$

\section{Effective Length}

The effectiveness of an antenna as a radiator or collector of electromagnetic wave energy is measured by its effective duration (Tang et al., 2016b). The effective length $\left(L_{e}\right)$ of a receiving antenna can be determined using calculations for induced voltage and incident field (2):

$$
L_{e}=\frac{\text { Opencricuit voltage }}{\text { incident electric field int ensity }}
$$

\section{Effective Aperture}

The effective aperture of the EM wave transmitting antenna must be large enough to absorb all of the power (Tang et al., 2016a). The plane wave's Poynting vector, or power density, is $\mathrm{S}$ watts per square meter and the helical antenna's field, $A_{p}$, is a square meter. Equation (Tang et al., 2016b) gives the obtained power (3).

Received power $=S A_{p}$

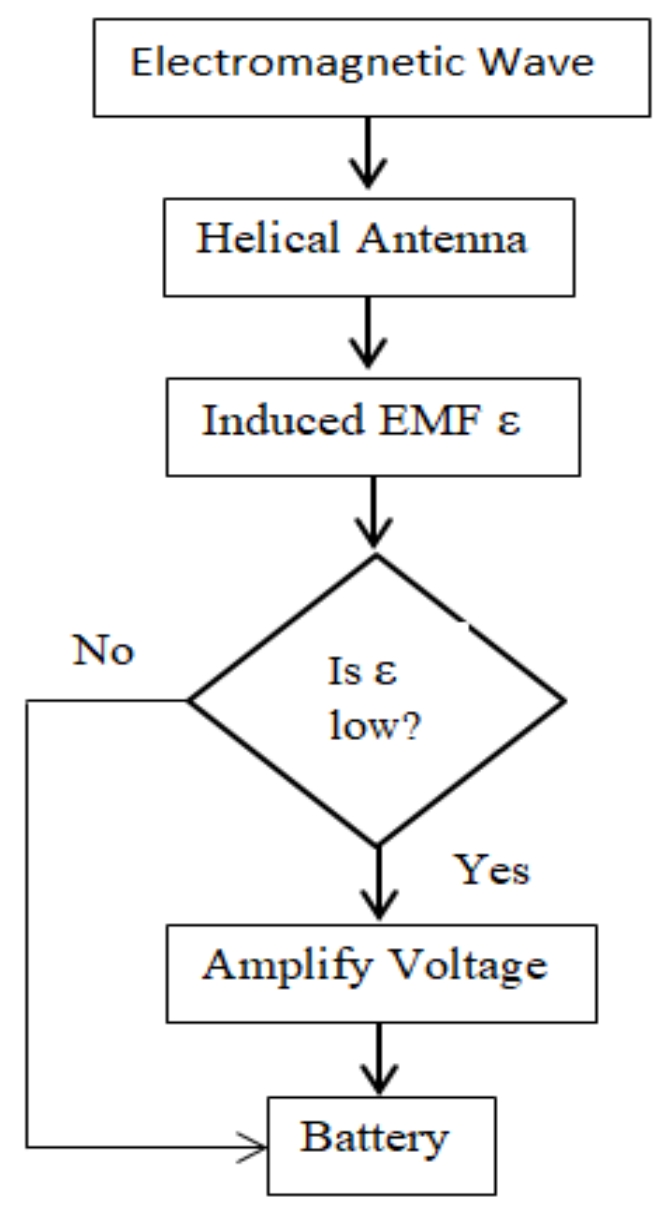

Fig. 2: Flow chart of the proposed work 


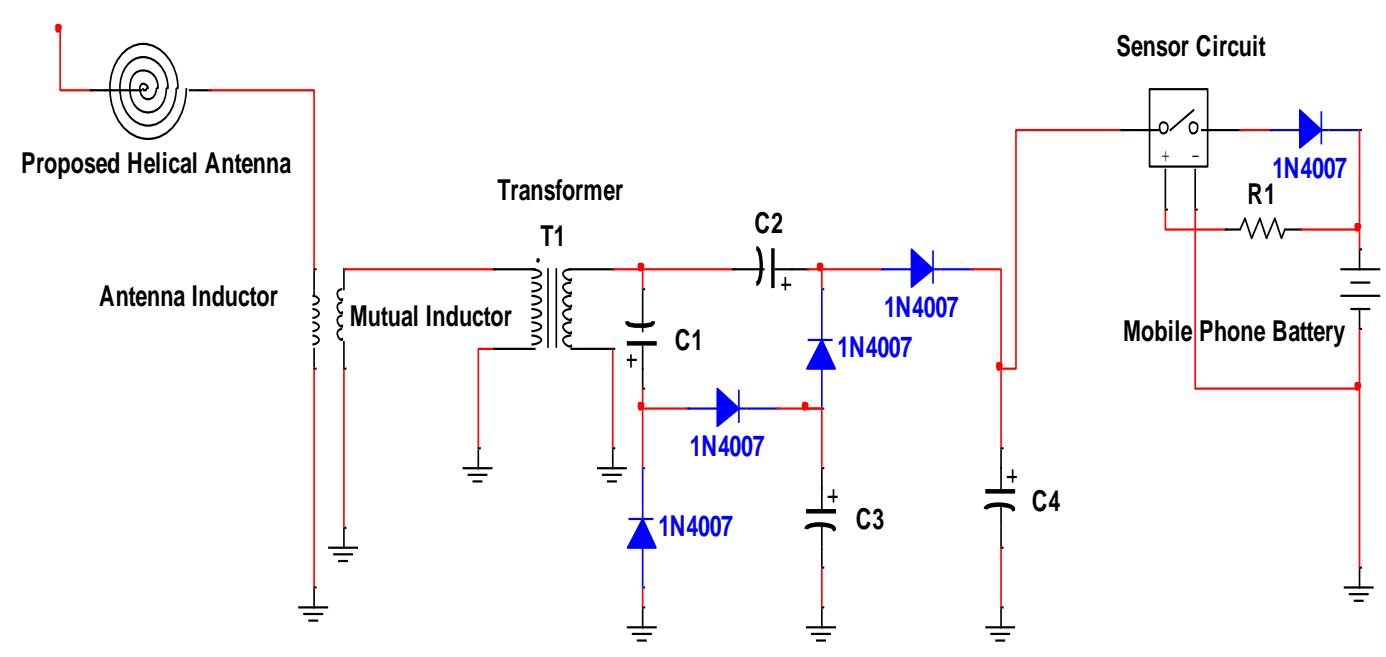

Fig. 3: Theoretical circuit design of the proposed model

\section{Antenna Directivity}

An antenna's Directivity (D) is defined as the ratio of the antenna's radiation intensity in one direction to the averaged radiation intensity in all directions, as given by Eq. (4). The cumulative power radiated $\left(P_{\mathrm{rad}}\right)$ by the antenna divided by $4 \pi$ gives the average radiation intensity (Guo et al., 2016).

$D=\frac{4 \pi \varphi_{\max }}{P_{r a d}}=\frac{4 \pi \varphi_{\max }}{4 \pi \varphi_{0}}$

Here, $\varphi_{\max }=$ the maximum radiation intensity, when receiving and transmitting antennas are in the same direction. $\varphi_{0}=$ the radiation intensity for isotropic antenna.

\section{Antenna Gain}

Antenna gain is defined (Guo et al., 2016) by Eq. (5):

$G=\frac{\text { Radiationintensity in a given direction }}{\text { Averagetotal input power }}$

Antenna gain $(G)$ is dependent on the directivity of the antenna shown in Eq. (6):

Gain, $G=k D$

Here,

$k=$ The Efficiency Factor and

$D=$ The directivity of the antenna

If an antenna has no losses like ohmic, or dielectric mismatch i.e., $100 \%$ efficiency, then directivity and gain are the same (Guo et al., 2016).

\section{Absorption Ratio of Receiving Antenna}

The effective aperture of a helical antenna is approximately 50\%. The physical aperture and the effective aperture are equal if there is no thermal failure and the field is in motion and optimum directivity is obtained (Guo et al., 2016).

$\gamma=\frac{(A e) \max }{A_{p}}$

Where,

$\gamma=$ Absorption ratio

$A_{e}=$ Effective aperture

$A_{p}=$ Physical aperture

\section{Collecting Aperture of Receiving Antenna}

Due to effective, scattering and aperture loss, power lost by the receiving antenna is lost as heat in load resistance, radiation resistance, and antenna loss resistance (Guo et al., 2016). The equation gives the collecting aperture (8).

Collecting aperture, $A_{c}=A_{e}+A_{s}+A_{L}$

Here,

$A c=$ Collecting aperture

$A e=$ Effective aperture,

$A_{s}=$ Scattering aperture,

$A_{L}=$ Loss apertures

\section{Flow Chart of the Work}

The flow chart by which the proposed model has been designed is shown in Fig. 2 and 3. The ambient electromagnetic waves would be picked up by the helical 
antenna. The receiving circuit of the antenna will experience a very low voltage as a result of the electromagnetic waves. This induced voltage is not enough for charging a device. This induced voltage is multiplied four times in this amplified circuit and then connected to the battery of that device.

\section{Theoretical Circuit Design}

The ambient waves are received by the proposed helical antenna and a small voltage is induced in the inductor. A step-up transformer is used to amplify this induced voltage. $\mathrm{R}_{1}$ 's value changes automatically in response to the induced EMF in the circuit. A sensor is used to control the switching circuit. If the remaining charge is less than $20 \%$ of the total battery charge, the sensor sends a signal to the switching circuit. Then the switch becomes closed and this state will continue until $2 \mathrm{~h}$, which can be modified by the user using a timer circuit. After $2 \mathrm{~h}$, the switching circuit will operate as an open circuit and then as a close circuit if the previous condition is met. By implementing this model, charging problems can be reduced.

\section{Design of Helical Antenna and Specification}

Figure 4 shows the configuration of the helical antenna. A circular ground plane and a cylindrical helix consisting of vertical strips of uniform width (w) make up the structure. For right-hand circular polarization, the helix is rolled in the Right-Hand direction (RHCP).

The detailed dimensions of the helix are given as follows:
$D=$ The diameter of the helix,

$S=$ The spacing between the turns (center-to-center),

$\alpha=$ The pitch angle $(\alpha=\arctan (S / \pi D))$

$C=$ The circumference of the helix $(C=P D)$,

$N=$ The number of turns and

$H=$ The total height of the antenna $(H=N S)$

\section{Induced Voltage}

The magnetic field differed over time when the antenna was at rest, with usual creating an angle with the plane of the antenna. The magnetic field differed with frequency and was determined using Eq. (9):

$$
B=B_{0} \sin \omega t
$$

Table 1: The design specifications of the $10 \mathrm{GHz}$ helical antenna

\begin{tabular}{ll}
\hline Parameters & Value \\
\hline Dielectric constant $\left(\varepsilon_{\mathrm{r}}\right)$ & 2.2 \\
Pitch angle $(\propto)$ & $13^{\circ}$ \\
Wavelength $(\lambda)$ & $0.375 \mathrm{~m}$ \\
Circumference $(\mathrm{C})$ & $0.13 \mathrm{~m}$ \\
Number of turns $(\mathrm{N})$ & 10 \\
Spacing between turns $(\mathrm{S})$ & 0.0 \\
Height of helical antenna $(\mathrm{H})$ & 30 \\
Ground Plane $(0.75 \lambda)$ & 0.03
\end{tabular}

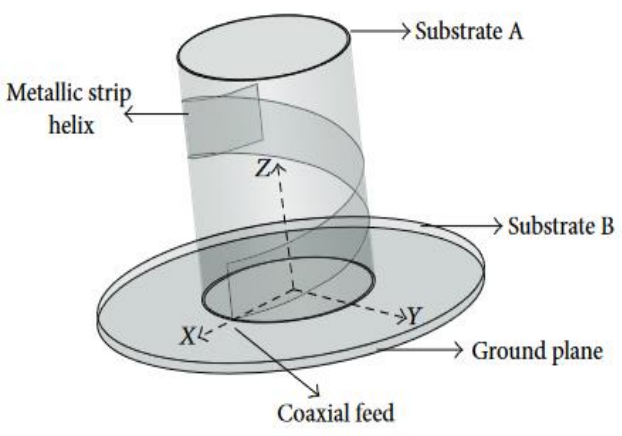

(a)

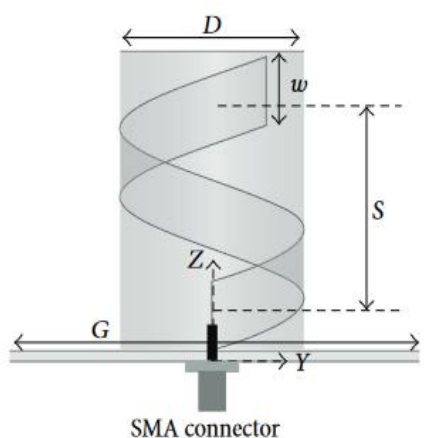

(b)

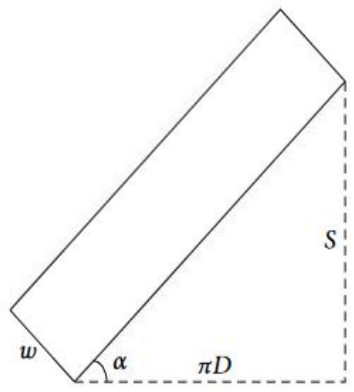

(c)

Fig. 4: Geometry of the proposed helical antenna (Guo et al., 2016). (a) 3D view. (b) Side view. (c) Unrolled helix of one turn 
Now, EMF Voltage in a rotating helical antenna in a time-dependent magnetic field is given by Eq. (10):

$$
\begin{aligned}
& \varepsilon=f\left[E \cdot d l=-\int_{S} \frac{\partial B}{\partial t} \cdot d s+\int_{C}(v \times B) \cdot d l\right. \\
& \varepsilon=E_{t}+E_{m}-\int_{S} \frac{\partial B}{\partial t} \cdot d s+\int_{C}(v \times B) \cdot d l \\
& =-\int_{S} \frac{\partial}{\partial t}\left(B_{0} \sin \omega t\right) \cdot d s+\omega \pi r^{2} B_{0} \sin ^{2} \omega t \\
& =-\omega \pi r^{2} B_{0} \cos \theta \cos \omega t+\omega t \pi r^{2} B_{0} \sin ^{2} \omega t \\
& =-\omega \pi r^{2} B_{0} \cos { }^{2} \omega t+\omega \pi r^{2} B_{0} \sin ^{2} \omega t \\
& =-\omega \pi r^{2} B_{0}\left[\cos ^{2} \omega t-\sin ^{2} \omega t\right] \\
& \varepsilon=-\omega \pi r^{2} B_{0}[\cos 2 \omega t]
\end{aligned}
$$

For fixed helical antennas, the loop was at rest, i.e., $v=0$, and the voltage in a closed path was referred to as the Electromotive Force (EMF). The voltage around a helical antenna is calculated using the Eq. (11):

$$
\begin{aligned}
& \int \mid E \cdot d l=-\int_{S} \frac{\partial}{\partial t} \cdot\left(B_{0} \sin \omega t\right) \cdot d s=-\omega \cos \omega t \int B_{0} \cdot d S \\
& =-\omega \cos \omega t \cdot B_{0} \cos \omega t \int d S=-\omega \pi r^{2} B_{0} \cos \theta \cos \omega t \\
& =-\omega \pi r^{2} B_{0} \cos ^{2} \omega t \int\left[E \cdot d l==-\omega \pi r^{2} B_{0} \cos ^{2} \omega t\right.
\end{aligned}
$$

\section{Simulated Results}

\section{Helix Antenna Height Against Number of Turns}

The cumulative height of the proposed helix antenna was determined using the equation $\mathrm{H}=\mathrm{NS}$ at three normalized circumferences of $\mathrm{C} /=0.94, \mathrm{C} /=1.28$, and $\mathrm{C} /=$ 1.66 as seen in Fig. 5. It was obvious that when $\mathrm{N}$ ranged from 3 to 10, the smoothly rising height reached its maximum value. This meant that the overall height of the helical antenna was highly dependent on the turn separation.

\section{Axial Ratio Against Number of Turns}

As the number of loops $\mathrm{N}$ increased, the axial ratio for helix antennas decreased, as seen in Fig. 6.

As the number of loops $\mathrm{N}$ increased, the axial ratio of the helical antenna decreased. When the diameter $\mathrm{C}$ was close to a wavelength given by the equation, helix antennas with at least three turns were close to circular polarization in the $+\mathrm{z}$ direction (12):

$$
\frac{3 \lambda}{4} \leq C \leq \frac{4 \lambda}{3}
$$

The circumference $\mathrm{C}$ was selected such that the above inequalities approximately determined the helix antenna's operational bandwidth. For pitch angles of 12 to 14 degrees, the helix antenna worked well. The pitch angle was normally set to 13 degrees.

\section{Received Power Against Frequency}

Figure 7 shows the helical antenna's received radiation pattern at various wavelengths. At $\mathrm{N}=10$, the graph above was simulated. The obtained EM power is seen in solid colors against a frequency spectrum of 1.5 to $2.4 \mathrm{GHz}$. At $\mathrm{r}=0.04 \mathrm{~m}, \mathrm{r}=0.03 \mathrm{~m}$ and $\mathrm{r}=0.02 \mathrm{~m}$, the colors magenta, blue, red and black reflect the same relationship. The above graph shows that $\mathrm{r}=0.02 \mathrm{~m}$ or $\mathrm{r}=0.03 \mathrm{~m}$ is very effective for receiving maximum EM power.

\section{D Radiation Pattern of Proposed Helical Antenna}

Figure 8 shows the proposed helical antenna's 3D radiation pattern at $\mathrm{f}=2.4 \mathrm{GHz}, \mathrm{P}_{\max }=11.7 \mathrm{~dB}$, $\mathrm{P}_{\min }=-12.1 \mathrm{~dB}$, Azimuth $\left[-180^{\circ}: 180^{\circ}\right]$ and Elevation $[-$ $90^{\circ}: 90^{\circ}$, Azimuth $\left[-180^{\circ}: 180^{\circ}\right]$ and Elevation $\left[-90^{\circ}: 90^{\circ}\right]$.

The $\mathrm{X}$-axis is red, the $\mathrm{Y}$-axis is green and the $\mathrm{Z}$-axis is blue.

\section{Input Impedance Against Frequency}

The red line in Fig. 9 reflects the reactance, while the blue line represents the resistance of the proposed helical antenna. Figure 9 (a) shows a sharp change in impedance from $\mathrm{f}=1.5$ to $1.7 \mathrm{GHz}$. Following that, the frequency impedance remained almost constant, similar to zero. About 2.2 and $2.4 \mathrm{GHz}$, the magnitude of impedance was high at 9 (b). The transition in impedance from 1.5 to $1.7 \mathrm{GHz}$ was very sluggish. Between 1.8 and $2.0 \mathrm{GHz}$, the impedance varies dramatically in 9 (c). Impedance was nearly constant after $2.0 \mathrm{GHz}$. In 9 (d), the impedance changing rate was very high between 1.5 and $16.5 \mathrm{GHz}$, almost constant between 16.5 and $2.05 \mathrm{GHz}$, and mild between 2.05 and $2.4 \mathrm{GHz}$.

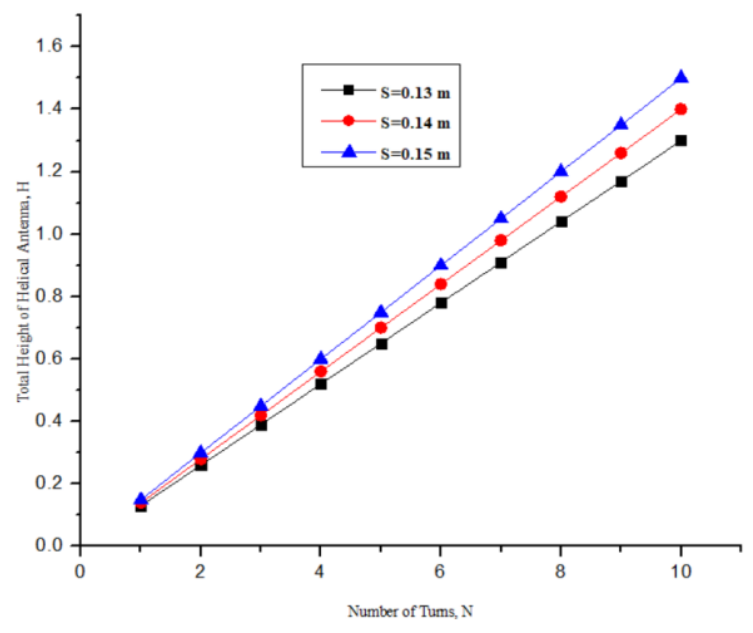

Fig. 5: Helix antenna height against the number of turns 


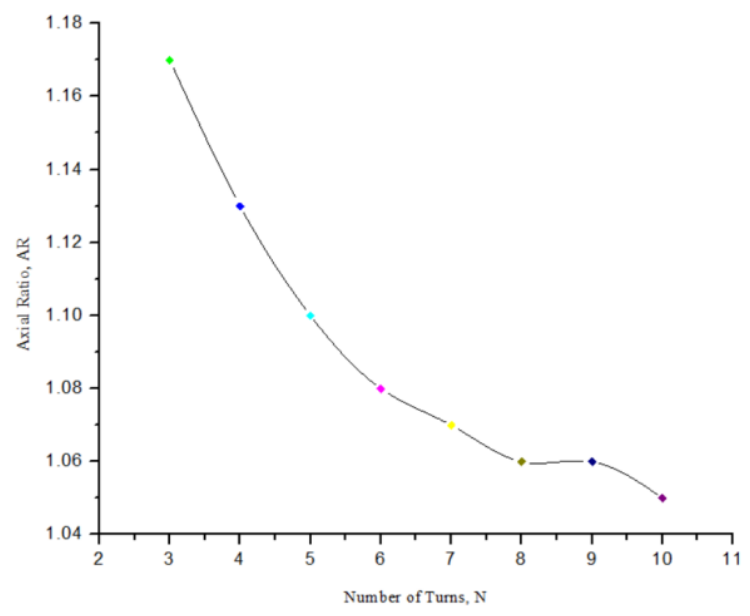

Fig. 6: Axial ratio against number of turns

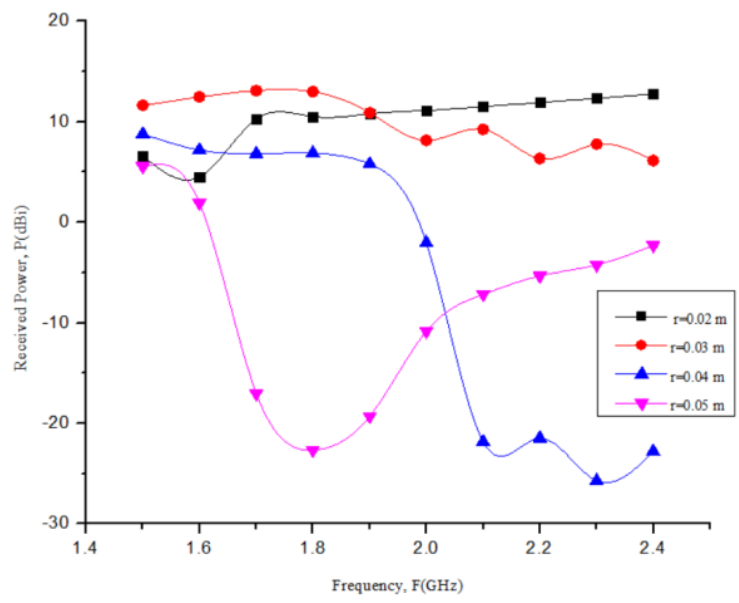

Fig. 7: Received power against frequency at $\mathrm{N}=0.05 \mathrm{~m}$

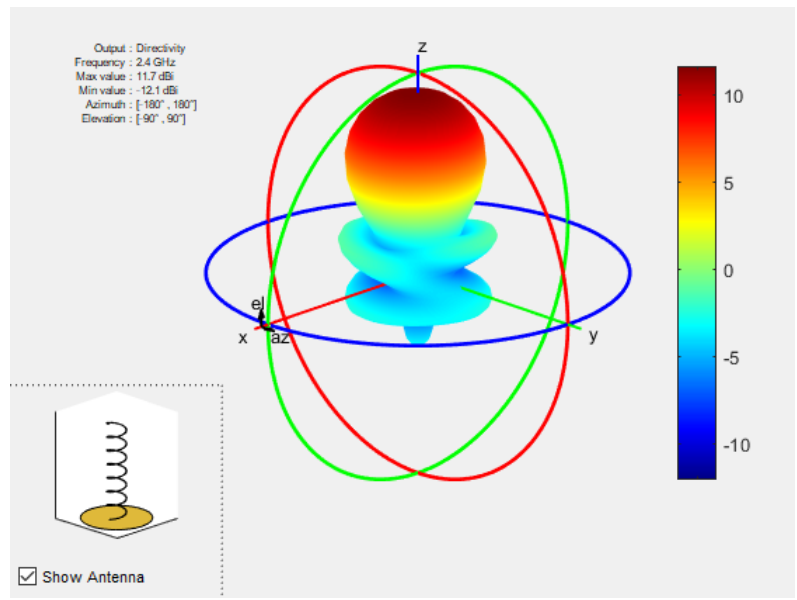

Fig. 8: 3D radiation pattern of a helical antenna at $\mathrm{f}=2.4 \mathrm{GHz}$ and $\mathrm{N}=10$ and $\mathrm{r}=0.05 \mathrm{~m}$

\section{VSWR Against Frequency}

Figure 10 shows the voltage standing wave ratio versus frequency. At $11 \mathrm{GHz}$, VSWR changed significantly between $\mathrm{f}=1.5$ and $1.68 \mathrm{GHz} 10$ (a). The magnitude of VSWR remained relatively unchanged after that frequency, at -5 dB. 10 (b) had a very high VSWR shifting pace, varying from 1.5 to $2 \mathrm{GHz}$. After that frequency, the shifting intensity was virtually constant and the magnitude was about $0 \mathrm{~dB}$. In 10 (c), the VSWR was normally moving between 1.5 and $1.9 \mathrm{GHz}$. The VSWR started to fluctuate rapidly after that frequency. At 11 (d) VSWR, the switching rate from 1.5 to $16.5 \mathrm{GHz}$ was incredibly fast. From 16.5 to $2.03 \mathrm{GHz}$, the changing rate was almost constant, with a magnitude of almost $3 \mathrm{~dB}$, and from 2.05 to $2.4 \mathrm{GHz}$, the changing rate was medium.

\section{Return Loss Against Frequency}

In figure 11, the return loss was plotted against frequency. In the 11 (a) between $\mathrm{f}=1.5$ and $1.63 \mathrm{GHz}$, return loss improved significantly. At that frequency, the degree of return loss changed slowly near $5 \mathrm{~dB} .11$ (b) has a very high changing rate of return loss, varying from 1.5 to $2.0 \mathrm{GHz}$. The changing rate of the return loss at that frequency was very low, with a magnitude of nearly $6 \mathrm{~d} \mathrm{~B}$. In 11(c), the return loss changed naturally between 1.5 and $1.75 \mathrm{GHz}$. After this frequency, the return loss changed dramatically. The changing rate of return loss was medium from 1.5 to $16.5 \mathrm{GHz}$ and from 16.5 to $2.03 \mathrm{GHz}$, the changing rate was almost constant and the magnitude was almost $5 \mathrm{~dB}$. The rate of change from 16.5 to $2.03 \mathrm{GHz}$ was nearly constant, with a magnitude of almost $5 \mathrm{~dB}$ and the rate of change from 2.05 to $2.4 \mathrm{GHz}$ was mild.

\section{Charge Distribution of Helical Antenna}

The blue color depicts the reflecting point of the proposed helical antenna shown in Fig. 12. There are 7 turns which are indicated by the black color. On the right side, there is a scale of charge distribution in $\mathrm{nC} / \mathrm{m}$.

\section{Azimuthal Radiation Patterns of the Proposed Helical Antenna}

The azimuthal radiation patterns of the proposed helical antenna are shown in Fig. 13.

\section{Elevation Radiation Patterns of the Proposed Helical Antenna}

The elevation radiation patterns of the proposed helical antenna are shown in Fig. 14 and 15.

The antenna patterns had a directivity of $12.2 \mathrm{~dB}$ for the same operating frequency, as shown in Fig. 14. Furthermore, the majority of the energy was directed in the positive $z$-direction, with side lobes that were more than $6.4 \mathrm{~dB}$ below the main lobe. The polar form, on the 
Pankaj Chandra Kar et al. / American Journal of Engineering and Applied Sciences 2022, 15 (1): 9.22 DOI: 10.3844/ajeassp.2022.9.22

other hand, is shown in Fig. 14, and the simulation results in the directivity of $12.2 \mathrm{~dB}$. The simulation results in the

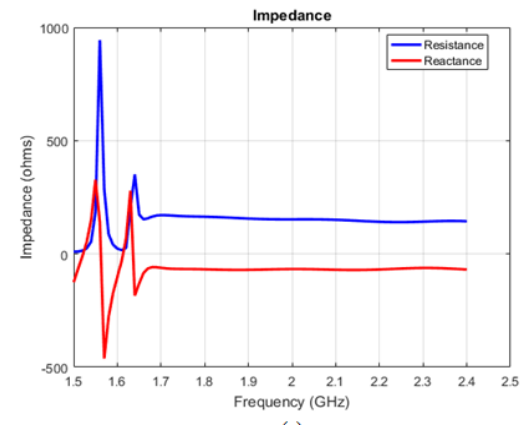

(a)

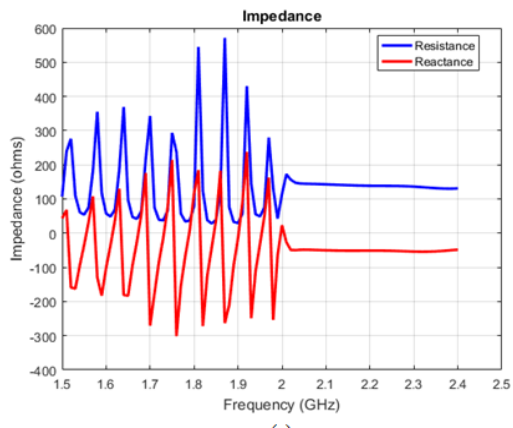

directivity of $12.2 \mathrm{~dB}$ and a beam width of 32.3 degrees for a 10-turn antenna.

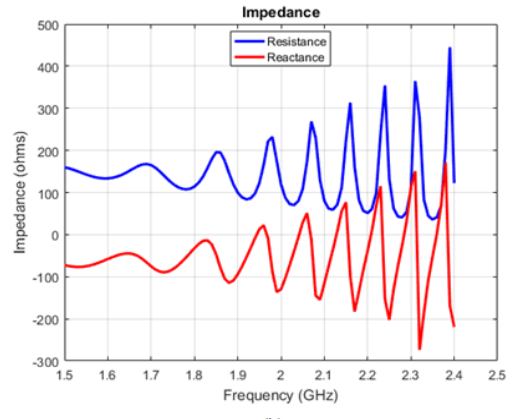

(b)

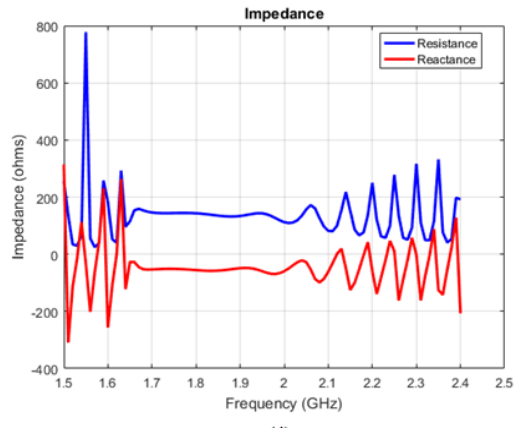

Fig. 9: Input impedance against frequency of the proposed helical antenna at $\mathrm{N}=10$ (a) $\mathrm{r}=0.02 \mathrm{~m}(\mathrm{~b}) \mathrm{r}=0.03 \mathrm{~m}(\mathrm{c}) \mathrm{r}=0.04$ $\mathrm{m}(\mathrm{d}) \mathrm{r}=0.05 \mathrm{~m}$

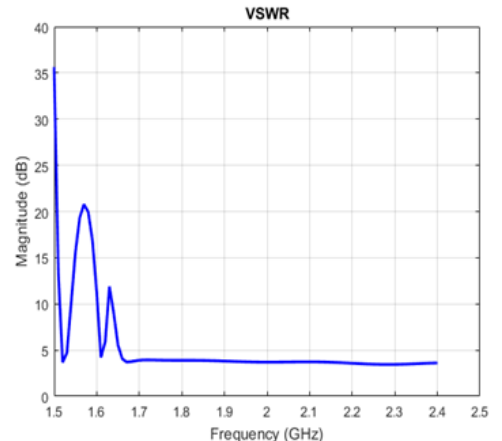

(a)

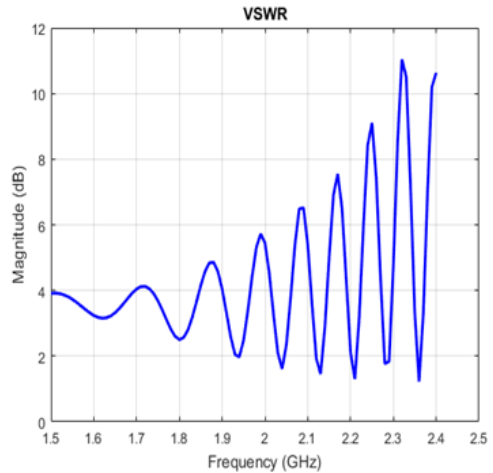

(c)

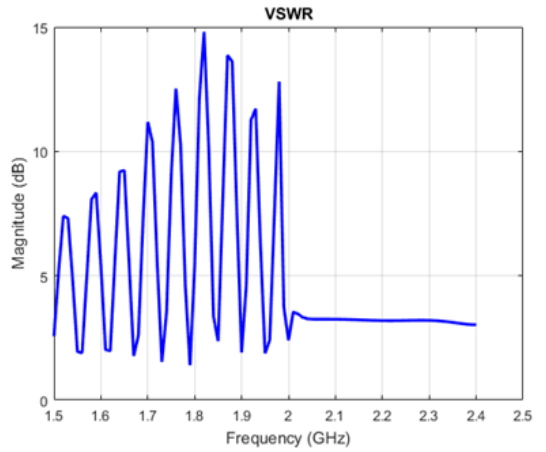

(b)

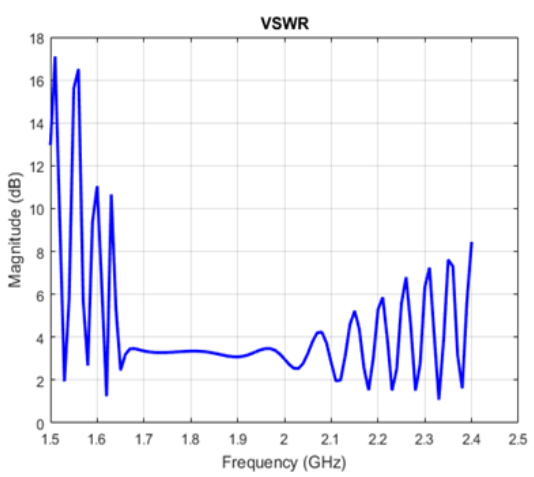

(d)

Fig. 10: VSWR against frequency of the proposed helical antenna at $N=10$ (a) $r=0.02 \mathrm{~m}$ (b) $r=0.03 \mathrm{~m}$ (c) $r=0.04 \mathrm{~m}$ (d) $r=0.05 \mathrm{~m}$ 


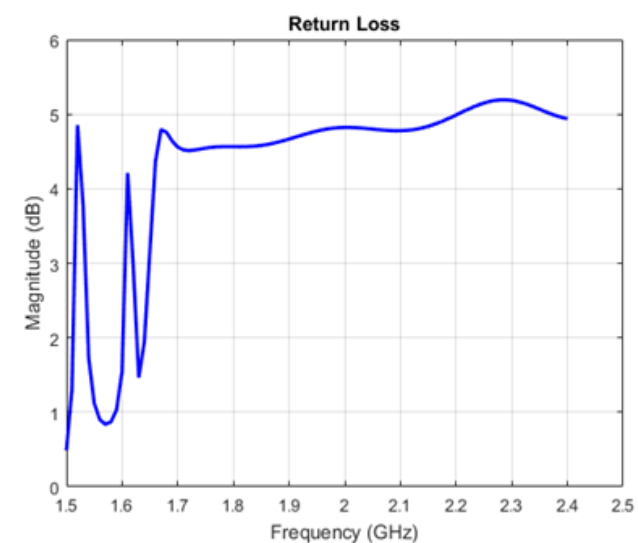

(a)

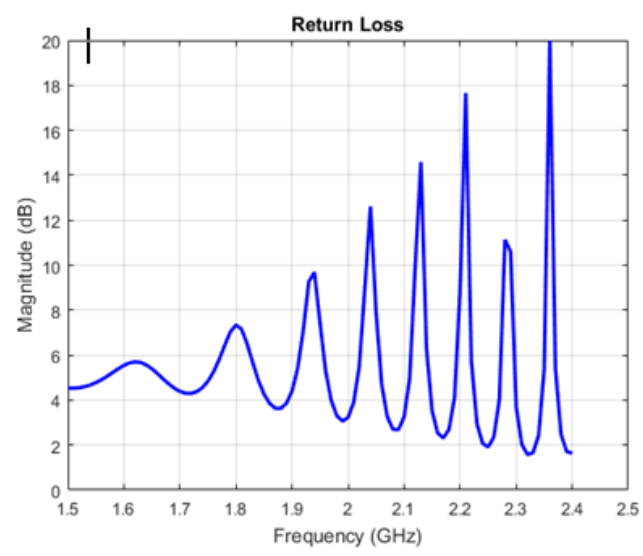

(c)

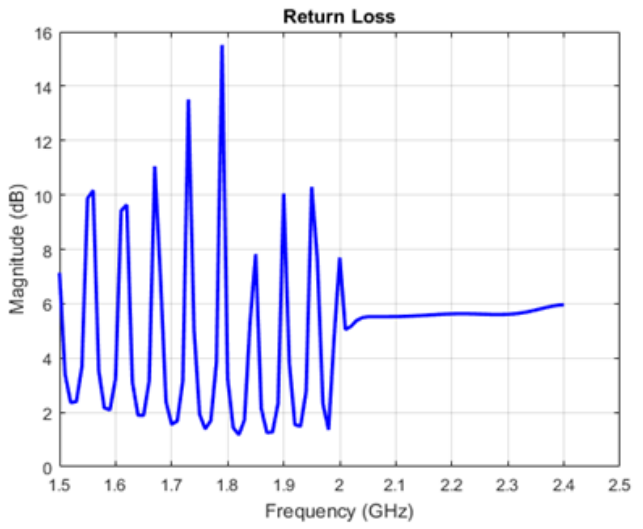

(b)

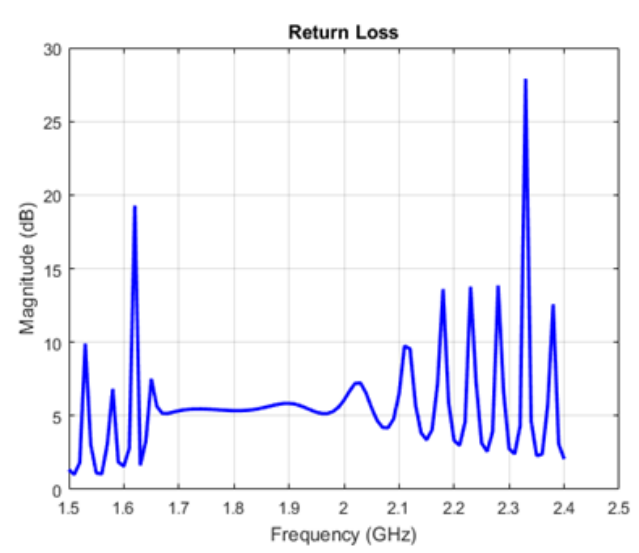

(d)

Fig. 11: Return loss against frequency of the proposed helical antenna at $N=10$ (a) $r=0.02 \mathrm{~m}$ (b) $r=0.03 \mathrm{~m}(\mathrm{c}) \mathrm{r}=0.04 \mathrm{~m}$ (d) $\mathrm{r}=0.05 \mathrm{~m}$

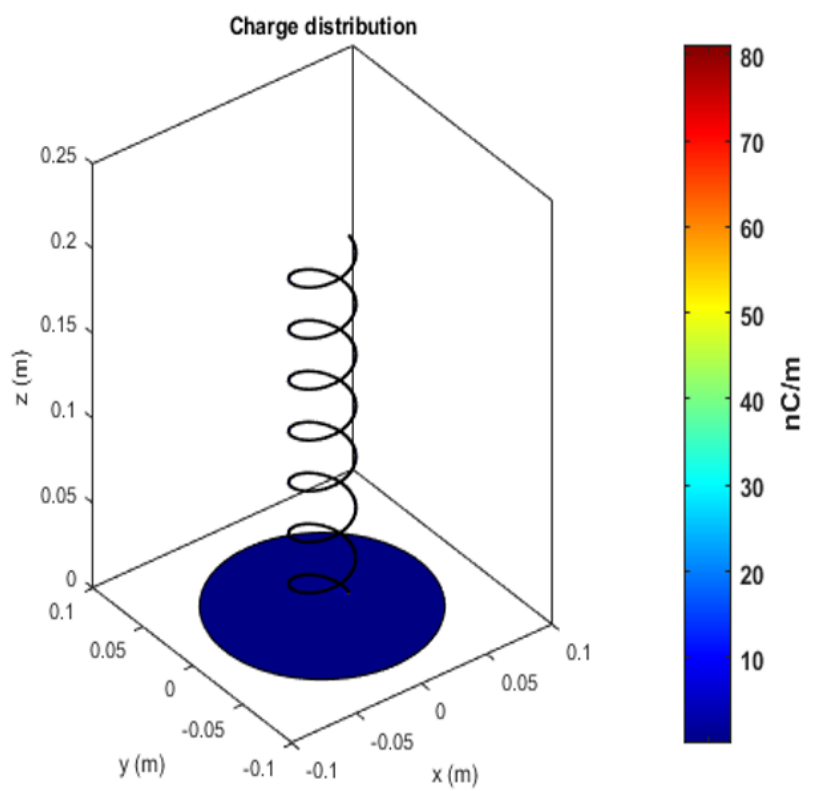

Fig. 12: Charge Distribution of the proposed helical antenna at $\mathrm{f}=2.4 \mathrm{GHz}, \mathrm{r}=0.05 \mathrm{~m}$ and $\mathrm{N}=10$ 


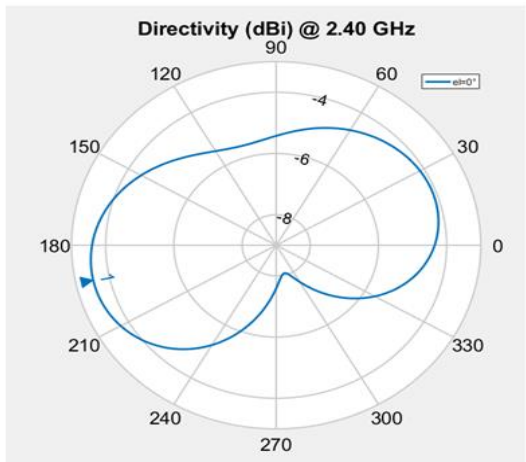

(a)

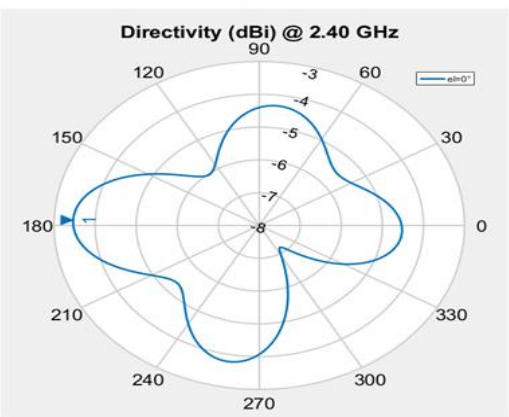

(c)

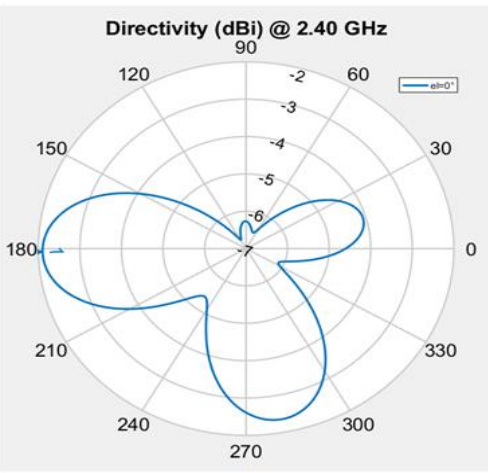

(b)

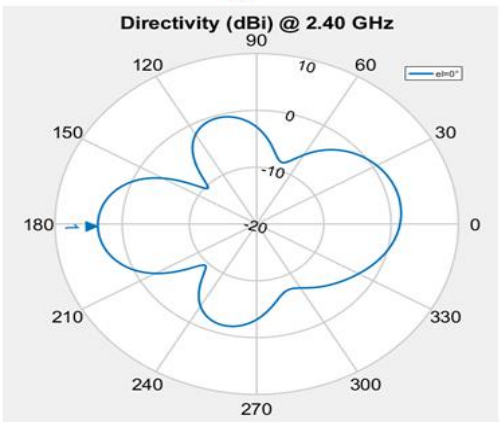

(d)

Fig. 13: Radiation patterns of the proposed helical antenna at $\mathrm{N}=10$ (a) $\mathrm{f}=2.4 \mathrm{GHz}, \phi=0$ oplane, $\mathrm{r}=0.02 \mathrm{~m}(\mathrm{~b}) \mathrm{f}=2.4 \mathrm{GHz}, \phi=0$ 。 plane, $r=0.03 \mathrm{~m}(\mathrm{c}) \mathrm{f}=2.4 \mathrm{GHz}, \phi=0$ oplane, $\mathrm{r}=0.04$ (d) $\mathrm{f}=2.4 \mathrm{GHz}, \phi=0 \circ$ plane, $\mathrm{r}=0.05 \mathrm{~m}$

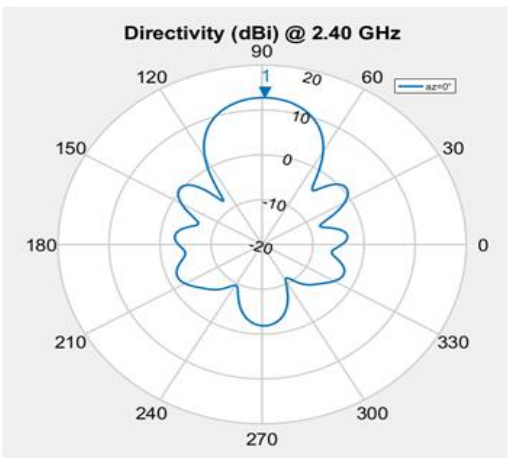

(a)

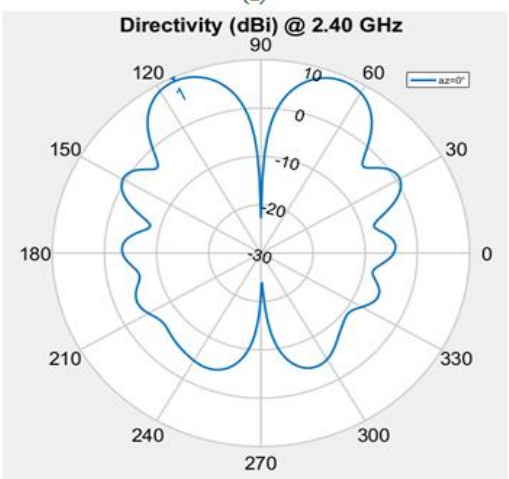

(c)

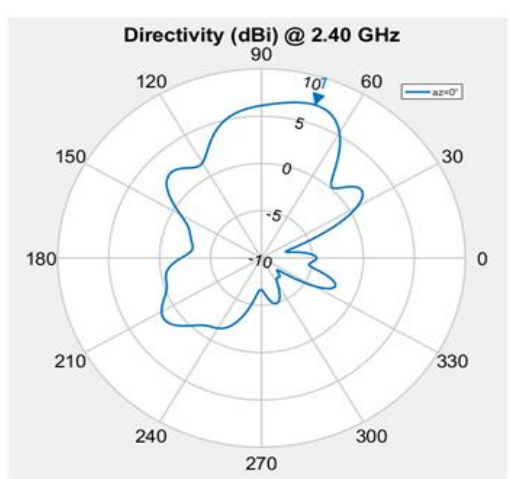

(b)

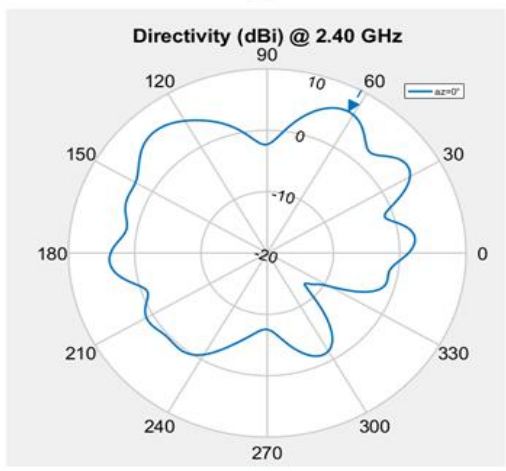

(d)

Fig. 14: Radiation patterns of the proposed helical antenna at $\mathrm{N}=10$ (a) $\mathrm{f}=12.4 \mathrm{GHz}, \phi=0^{\circ}$ plane, $\mathrm{r}=0.02 \mathrm{~m}(\mathrm{~b}) \mathrm{f}=2.4 \mathrm{GHz}, \phi=0^{\circ}$ plane, $r=0.03 \mathrm{~m}(\mathrm{c}) \mathrm{f}=2.4 \mathrm{GHz}, \phi=0^{\circ}$ plane, $\mathrm{r}=0.04(\mathrm{~d}) \mathrm{f}=2.4 \mathrm{GHz}, \phi=0^{\circ}$ plane 


\section{Magnetic Field Strength Against Distance}

In 15 (a) and (b), the magnetic field strength was plotted against distance while the helix antenna was fixed and revolving, respectively.

When the distance was about $3 \mathrm{~m}$, the mean magnetic field for both fixed helix was about $50 \mathrm{~T}$, as shown by the blue color and the minimum magnetic field was about $12 \mathrm{~T}$, as indicated by the black color, when the distance was about $25 \mathrm{~m}$.

When $\mathrm{n}=1$, orange when $\mathrm{n}=2$ and blue when $\mathrm{n}=3$, there are almost three colors: Black when $n=1$, orange when $\mathrm{n}=2$ and blue when $\mathrm{n}=3$. The mean magnetic field strength for the spinning helix was nearly $60 \mathrm{~T}$ when the distance was $5 \mathrm{~m}$, as shown by the magenta color and the minimum magnetic field was $17 \mathrm{~T}$ when the distance was $28 \mathrm{~m}$. the number of turns increased, and the value of magnetic field strength increased and as the distance increased, the magnetic field strength decreased. This happened mainly due to the antenna polarization.

\section{Induced Voltage Against Distance}

As the helix antenna rotated, the caused voltage was plotted against distance in Fig. 16. The generated voltage varied as the number of turns varied for various radius helix antennas, (a) $r=0.02 \mathrm{~m}$, (b) $r=0.03 \mathrm{~m}$, (c) $r=0.04$ $\mathrm{m}$, (d) $\mathrm{r}=0.05 \mathrm{~m}$. The overall induced voltage in Fig. (a) was almost 9 volts, which was used for low voltage applications, such as cell phones.

The overall induced voltage in Fig. 16 (b) was almost 18 volts, which was used for medium voltage applications, such as laptops. The maximum induced voltage was approximately 35 volts and 55 volts, respectively, as seen in Fig. 16(c) and (d), and was once used in high-voltage equipment like televisions. The generated voltage varies with the number of flips. Due to antenna polarization, the induced voltage fluctuates, so the graph is not linear. The above relationship was discovered after studying each Table 1.

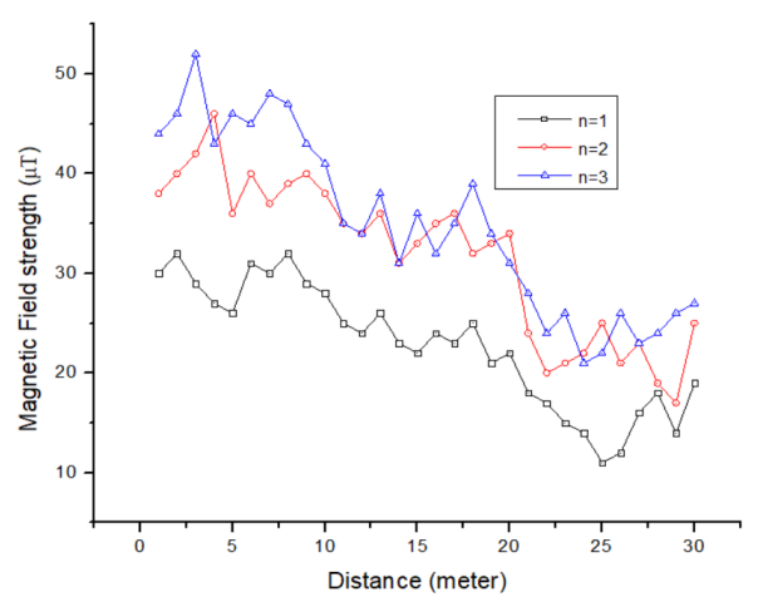

(a)

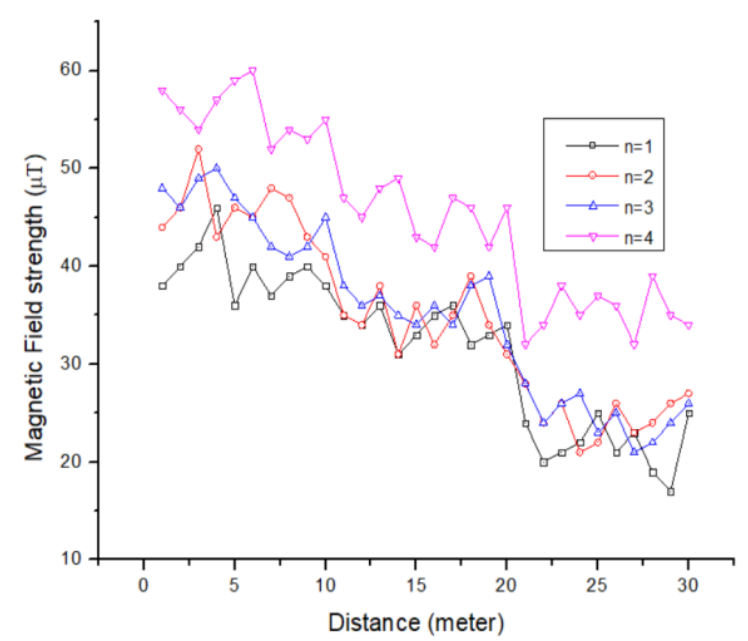

(b)

Fig. 15: Magnetic field strength against distance when the helix antenna is (a) fixed and (b) rotating

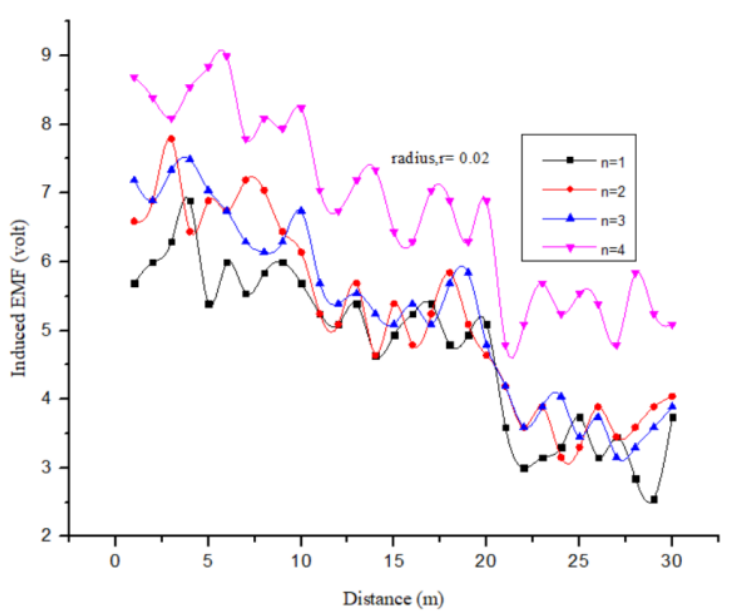

(a)

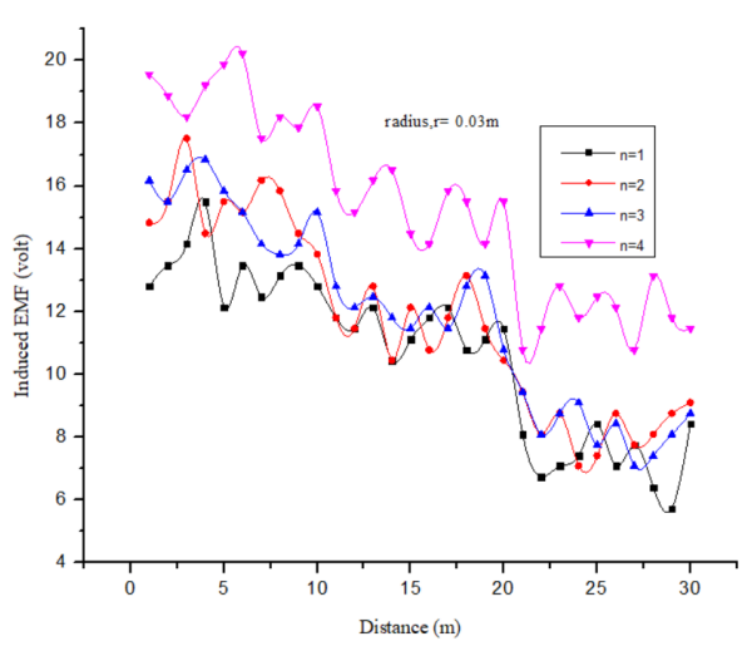

(b) 


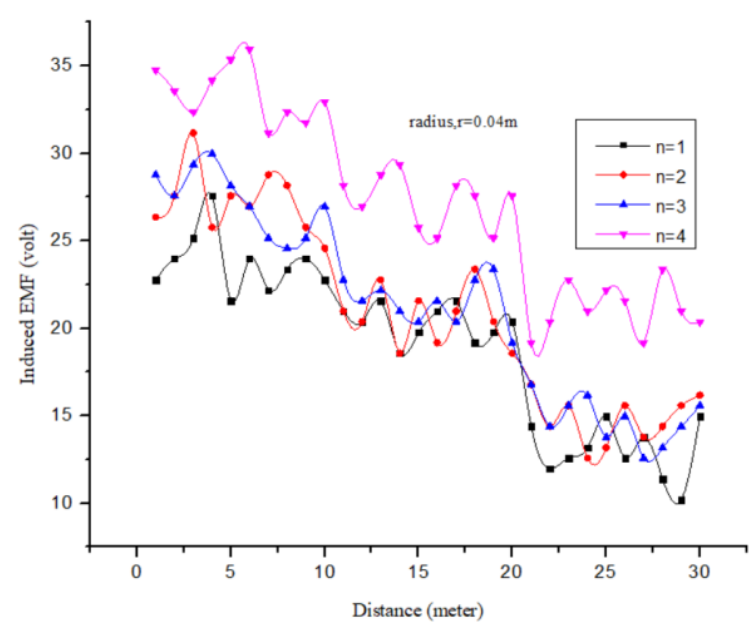

(c)

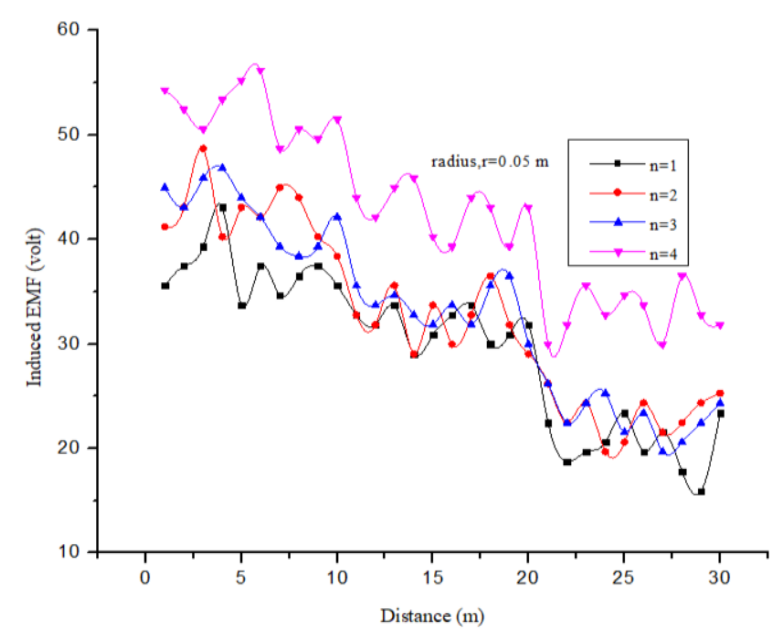

(d)

Fig. 16: Induced voltage against distance. When radius of helix is (a) $0.02 \mathrm{~m}$ (b) $0.03 \mathrm{~m}$ (c) $0.04 \mathrm{~m}$ (d) $0.05 \mathrm{~m}$

\section{Discussion}

This work presents a theoretical model for charging an electronic device from the ambient EM waves. The results simulated by Matlab ${ }^{\circledR}$ are discussed in several ways: 4.1 helix antenna heights against the number of turns 4.2 Axial RATIO against the number of turns 4.3 received power against frequency $4.43 \mathrm{D}$ radiation pattern of proposed helical antenna 4.5 input impedance against frequency 4.6 VSWR against frequency 4.7 return loss against frequency 4.8 charge distribution of helical antenna 4.11 magnetic Field strength against distance 4.12 induced voltage against distance. Using the "Network Signal Info" application, we collect the Induced magnetic field and EMF at various distances for various numbers of turns and plot their related graphs. No paper gave a clear concept about the antenna model for a wireless charger. In this study, we use a transformer to amplify the induced voltage and a voltage multiplier circuit for amplifying the voltage at 4 times the input voltage. This study is a continuation and a final stage of the exploration of charging an electronic device on different networks. This is an innovative model of using renewable energy. Other renewable energies like as solar cells etc. are not suitable anywhere.

\section{Conclusion}

There was an induced voltage in the proposed antenna. All kinds of radiated EM waves were received by the proposed helical antenna. As the number of turns increased, the induced voltage also increased. The incident EM waves were distorted by scattering, reflection, refraction, and other factors. There were no specific rules for inducing EM waves. EM waves were radiated from different electronic devices and these radiated waves induced voltage at the antenna inductor. In low-frequency waves, the induced EMF was high, while in high-frequency waves, it was low. Induced EMF and magnetic field increased as the number of turns increased and the diameter of the proposed helical antenna increased. Antenna polarization affected those results.

Study limitations:

- Costing is very high

- Different types of transformers are needed for different devices

- It is difficult to find out such kind of transformer in real life

- Setting the value of time in the timer circuit is very difficult for an uneducated user

\section{Future Research}

Using the human body as an antenna, charge every electronic device from ambient EM waves.

\section{Acknowledgment}

P.C.K. and M.A.I. gratefully acknowledge the experimental support of the Electronics and Communication Engineering Lab, ICT Department, Comilla University, under the scope of an undergraduate research project. 


\section{Funding Information}

This research received no specific grant from any funding agency in the public, commercial, or not-forprofit sectors.

\section{Author's Contributions}

Pankaj Chandra Kar: Conceived the project idea and designed experimental works, conceived, and edited the manuscript.

Ariful Islam: Led the overall research works.

Amit Paul and Joydip Chakrabarti: Supported writing the preliminary manuscript.

Subrata Sutradhar: Supported calculation of the coverage area of the lift.

Fardin Teen Rahman: Fardin Teen Rahman supported writing the experimental setup.

\section{Ethics}

This article is original and contains unpublished material. The corresponding author confirms that all of the other authors have read and approved the manuscript and that no ethical issues are involved.

\section{References}

Beh, H. Z. Z., Covic, G. A., \& Boys, J. T. (2014). Investigation of magnetic couplers in bicycle kickstands for wireless charging of electric bicycles. IEEE Journal of Emerging and Selected Topics in Power Electronics, 3(1), 87-100. doi.org/10.1109/JESTPE.2014.2325866

Bettini, A. (2016). A Course in Classical Physics 1-Mechanics. Switzerland: Springer. doi.org/10.1007/978-3-319-29257-1

Browne, M. (2013). Schaum's Outline of Physics for Engineering and Science. McGraw-Hill Education. https://www.accessengineeringlibrary.com/content/b ook/9780071810906

Cloude, S. (1995). An introduction to electromagnetic wave propagation and antennas. Springer Science and Business Media. ISBN-10: 9780387915012.

Dai, H., Liu, Y., Liu, A. X., Kong, L., Chen, G., \& He, T. (2016, April). Radiation constrained wireless charger placement. In IEEE Infocom 2016-The 35th Annual IEEE International Conference on Computer Communications (pp. 1-9). IEEE. doi.org/10.1109/INFOCOM.2016.7524385

Dennison, B. A., Erb, T. A., \& Jenkins, P. L. (2002). Television viewing and television in the bedroom are associated with overweight risk among low-income preschool children. Pediatrics, 109(6), 1028-1035. doi.org/10.1542/peds.109.6.1028
Guo, P., Liu, X., Tang, S., \& Cao, J. (2016). Concurrently wireless charging sensor networks with efficient scheduling. IEEE Transactions on Mobile Computing, 16(9), 2450-2463. doi.org/10.1109/TMC.2016.2624731

Huang, Y., Liu, C., Liu, S., \& Xiao, Y. (2019, October). A Selectable Regional Charging Platform for Wireless Power Transfer. In IECON 2019-45th Annual Conference of the IEEE Industrial Electronics Society (Vol. 1, pp. 4445-4450). IEEE. doi.org/10.1109/IECON.2019.8927712

Jiang, H., Brazis, P., Tabaddor, M., \& Bablo, J. (2012, November). Safety considerations of wireless charger for electric vehicles-A review paper. In 2012 IEEE Symposium on Product Compliance Engineering Proceedings (pp. 1-6). IEEE. doi.org/10.1109/ISPCE.2012.6398288

Kar, P. C., Islam, M., \& Paul, A. (2021). Experimental Circuit Model for Increasing the Signal Strength level of a Mobile Phone into a Lift [Abstract]. International Journal of Advanced Trends in Computer Science and Engineering, 10(2), marchApril, 1065-1072. doi.org/10.30534/ijatcse/2021/821022021

Kindl, V., Frivaldsky, M., Zavrel, M., \& Pavelek, M. (2020). Generalized design approach on industrial wireless chargers. Energies, 13(11), 2697. doi.org/10.3390/en13112697

Kraus, J. D. (1949). The helical antenna. Proceedings of the IRE, 37(3), 263-272. doi.org/10.1109/JRPROC.1949.231279

Kraus, J. D., \& Williamson, J. C. (1948). Characteristics of helical antennas radiating in the axial mode. Journal of Applied Physics, 19(1), 87-96. doi.org/10.1063/1.1697878

Nakano, H., Takeda, H., Honma, T., Mimaki, H., \& Yamauchi, J. (1991). Extremely low-profile helix radiating a circularly polarized wave. doi.org/10.1109/APS.1990.115206

Norman, T. L. (2014). Integrated Security Systems Design: A Complete Reference for Building Enterprise-wide Digital Security Systems. Butterworth-Heinemann.

Purcell, E. M., Purcell, E. M., Purcell, E. M., \& Purcell, E. M. (1965). Electricity and magnetism (Vol. 2, pp. 92-94). New York: McGraw-Hill.

Tang, X., Feng, B., \& Long, Y. (2016a). The analysis of a wideband strip-helical antenna with 1.1 turns. International Journal of Antennas and Propagation, 2016. doi.org/10.1155/2016/5950472

Tang, X., He, Y., \& Feng, B. (2016b). Design of a wideband circularly polarized strip-helical antenna with a parasitic patch. IEEE Access, 4, 7728-7735. doi.org/10.1109/ACCESS.2016.2628044 
Pankaj Chandra Kar et al. / American Journal of Engineering and Applied Sciences 2022, 15 (1): 9.22 DOI: 10.3844/ajeassp.2022.9.22

Zeain, M. Y., Abu, M., Zakaria, Z., Al-Gburi, A. J. A., Syahputri, R., Toding, A., \& Sriyanto, S. (2020). Design of a wideband strip helical antenna for $5 \mathrm{G}$ applications. Bulletin of Electrical Engineering and Informatics, 9(5), 1958-1963. doi.org/10.11591/eei.v9i5.2055
Zeng, H., Liu, Z., Hou, Y., Hei, T., \& Zhou, B. (2017). Optimization of magnetic core structure for wireless charging coupler. IEEE Transactions on Magnetics, 53(6), 1-4. doi.org/10.1109/TMAG.2017.2657544 